\title{
Fertilizer supply chain in Ethiopia: structure, performance and policy analysis
}

\author{
Johanes U.I. Agbahey (1), Harald Grethe (1), Workneh Negatu (2) \\ (I) Agricultural and Food Policy Group, Universität Hohenheim, Germany \\ (2) Centre for Rural Development Studies of Addis Ababa University, Ethiopia
}

\begin{abstract}
In Ethiopia, less than $40 \%$ of farmers use fertilizer and those who do, apply rates significantly below those recommended. This low fertilizer use is primarily due to prices being two to three times higher than prices on the world markets. Reducing the price of fertilizer requires a sound understanding of the product's supply chain. This study investigates whether fertilizer is delivered to farmers in an efficient way and at the lowest possible costs using an institutional economics framework. It was conducted in the Arsi zone and relied on secondary data as well as primary data collected through interviews. The findings point out the presence of several formal and informal institutions regulating the market. A market monopoly at each stage of the supply chain and a striking correspondence between the central organization of the chain and the rise in left-over stocks were observed. This pinpoints the imperfect structure of the chain and a misallocation of resources locked up in fertilizer stockholding. In order to improve the demand estimation procedure, this study suggests that incentives should be instituted to enhance the reliability of the information transferred along the process. Additionally, expert knowledge used in the process should be well documented, stock inventories should not be limited to central warehouses and stockholding needs to be reduced.
\end{abstract}

Key words: supply chain, fertilizer, monopoly, cooperatives, Ethiopia

\section{Introduction}

Increased agricultural productivity in Sub-Saharan Africa ${ }^{1}$ (SSA) requires a range of measures including crop protection innovations and improved agronomic husbandries, but also the appropriate use of fertilizer ${ }^{2}$ and improved seeds (Vanlauwe et al., 20r4; Howard et al., 2003). Although none of these measures is likely to be effective if implemented in isolation, fertilizer is a critical input (Zerfu \& Larson, 2010). An increase in, and efficient use of, fertilizer has great potential to increase crop yields and improve land productivity (Barbier, 2000). Additionally, fertilizer use in SSA is very low and inadequate 
to compensate for the nutrients removed in harvested crops (Yamano \& Kijima, 2010). Indeed, the average fertilizer use intensity from 2000 to 2003 in SSA was 9 kilograms of nutrients per hectare (kg/ha), whereas it was $86 \mathrm{~kg} / \mathrm{ha}$ in Latin America, I04 kg/ha in South Asia and $142 \mathrm{~kg} / \mathrm{ha}$ in Southeast Asia (Crawford et al., 2006). In high income countries (Western Europe and USA), fertilizer use intensity is up to $288 \mathrm{~kg} / \mathrm{ha}$ on average (Hernandez and Torero, 20II). Therefore, potential productivity gains can be achieved by increasing fertilizer use in many parts of SSA without adverse environmental consequences (Mwangi, I996).

Fertilizer use in Ethiopia, as in most SSA countries, is very low due to several constraints. Matsumoto and Yamano (2009) summarized these constraints pointing to two groups. The first group is the market-based constraints, which suggest that farmers do not use fertilizer because of a relatively high fertilizer to crop price ratio. The second group, the non-market-based constraints, emphasizes farmers' lack of knowledge about fertilizer as well as land degradation, which lowers the returns to fertilizer application. In the Ethiopian case, although non-market constraints play a role, Dercon and Christiaensen (20II) clearly showed that the crucial point is market constraints. They demonstrated that over time the fertilizer-to-output price ratio has increased substantially. Thus, the search for effective and sustainable policies to promote fertilizer use in Ethiopia should involve measures to lower this price ratio. This means either reducing fertilizer purchasing prices or increasing farm gate output prices, or both (Namazzi, 2008). This study focuses on the potential for reducing fertilizer prices at farm level. Previous studies found farm gate prices of fertilizer in Ethiopia to be two to three times higher than prices on world markets (Gregory \& Bumb, 2006). However, none of these studies analyzed the structure of the supply chain for fertilizer in Ethiopia, in order to point out the constraints resulting in the observed high prices.

The structure of the fertilizer market in Ethiopia has changed over time. After its introduction in the country in 1967 , fertilizer importation and distribution was controlled by the government company known as the Agricultural Input Supply Corporation (AICO) and later renamed Agricultural Inputs Supply Enterprise (AISE). This state monopoly prevailed until the fall of the central planning in I99I (Matsumoto \& Yamano, 2009). Subsequently, the market was liberalized and private companies became involved (Spielman et al., 2010). However, in 200I, the private companies exited the market because of strong competition from companies subsidized by regional governments which entered the market in 1996 (Demeke et al., 1997). By 2005, facing an increasing deficit in their budget due to subsidies granted to their regional companies, regional governments decided to support agricultural cooperatives who were expected to be more efficient in delivering fertilizer to farmers. From 2006 onwards, cooperative unions (CU) became dominant actors of fertilizer import and their market share reached $75 \%$ in 2007/2008 (IFPRI, 20I2). However, in 2008, the Ethiopian federal government decided to coordinate all fertilizer import through only one company, in order to benefit from economies of scale by purchasing in bulk and save foreign currency (World Bank, 20II). The selection of the sole importer would be done every year by representatives of previous importers. 
Since the "sole importer" policy has come into force, the AISE has been awarded the position of importer every year, leaving the cooperatives with the role of fertilizer distribution (IFPRI, 20I2). Consequently, there is an implicit monopoly at each stage of the supply chain. Along with the new policy, government offices play a major role by regulating the chain, fixing marketing margins and prices, and monitoring the AISE and the cooperatives. Thus, the chain is centrally-organized although it involves both state and non-state organizations. This new structure has not yet been assessed. This paper using the framework of institutional economics first describes the institutions involved in the chain and then investigates the efficiency of the chain in delivering fertilizer to farmers in a timely manner and at the lowest possible costs. The paper is structured as follows. Section 2 provides a detailed description of the theoretical framework and the methods used in this study. Section 3 presents the findings and is followed by the discussion in Section 4. Finally, section 5 draws on the most important conclusions and derives policy options.

\section{Theoretical framework and Methods}

\section{Theoretical framework}

In this section, theories which discuss the role of the state in organizing the market are reviewed. Chang (2002) used the term "interventionist" for theories justifying state intervention, such as welfare economics and Keynesian economics. These theories support state involvement in the markets in order to correct the so-called "market failures". In their eyes, free markets as defined by neoclassical economics may not deliver a socially optimal resource allocation (Nedergaard, 2006). Thus, active state intervention is required to provide public goods, fight unemployment, reduce externalities and break monopolies (Chang, 2003). A fundamental criticism of these theories is that they see a market failure as a static rather than a dynamic outcome. Additionally, they ignore the impact of present state intervention on future developments of the market (Tanzi, 20II). In fact, the application of these theories in many countries over much of the past century showed that active state involvement to correct presumed market failures has often resulted in state monopolies and overly large public spending (Krueger, I99r).

In contrast to interventionist theories, neo-liberal theory supports a minimal state. The main argument is that the state is run by self-interested politicians and bureaucrats who have a partial attitude towards interest groups (Nedergaard, 2006). Thus, the assumption of an impartial and omnipotent state made by interventionist theories is not realistic. Neo-liberals support a minimal state based on the existence of "government failures" such as corruption, state monopoly, lack of infrastructure facilities and regulatory capture (Krueger, I99I). Although neo-liberals acknowledge the existence of market failures, they argue that government failures outweigh them. However, the underlying assumptions behind the neo-liberals' definition of state, market, institutions and politics, as well as their relationships is problematic from both theoretical and practical perspectives (Chang, 2002). In the 80's and the 90's many developing countries performed poorly due to the often schematic application of these theories through neo-liberal adjustment programs (Chang, 2009; Wolford et al., 2013). 
A third group of theories dealing with the role of the state is institutional economics. Within this field the market as well as the state are viewed as only two institutions among many others. Other institutions making up the whole system range from formal institutions such as law to informal institutions such as social conventions and their enforcement mechanisms that govern the behaviour of individuals in the society. From an institutional economics perspective, both market and governmental failures may not matter as much, as long as other institutions can regulate the economic system (Chang, 2002). In fact, market performance is determined by the institutional framework because institutions define and enforce the economic rules of the game (North, I995). Therefore, to assess the functioning of the market, one needs to understand the institutions and organizations that are engaged. The core of the theory that demarcates it from the classical and neoclassical schools is the shift of the ultimate unit of economic investigation from individual behaviour and exchange of commodities to individual action defined as trans-action (Commons, I931). Transactions occurring in the market are not seen here as a mere exchange of commodities but as the alienation and acquisition of property rights defined by society norms and working rules. The major contribution of institutional economics is the introduction of transaction costs into economic thinking (Eggertsson, 2013). The cost of exchange (transaction cost) depends on the institutions of a country (Coase, I998). In most developing countries where transaction costs are high, the institutionalism framework is more able to address questions of structural change and economic development (Hodgson, 2000).

In this study we adopt the institutional economics framework acknowledging that in Ethiopia, a country with high transaction costs, institutions play a significant role in determining the performance of the fertilizer market. Within the institutionalism framework, there are two streams: the old and the new institutionalism. The two streams can be differentiated based on whether the neoclassical paradigm of given individual motivation needs to be rejected or simply modified (Rutherford, I995). The old institutional economics is associated with the works of authors such as Thortstein Veblen, John Commons, Wesley Mitchell, Geoffrey Hodgson and John Galbraith. For them, individuals and their preference functions should not be taken as given because they are mutable (Hodgson, I998). Institutions shape individual motivation, conceptions and preferences, while individuals' interaction form institutions. Thus, institutions have both an upward and downward causation on individuals. The constitutive nature of institutions assumes that they embody certain values, such that individuals working under them internalise these values and change their individual motivation. Operating in the public sphere for instance would lead to internalising non-selfish values (Chang, 2002). A major criticism of the old institutional economics is the lack of a systematic and rigorous theory (Coase, I998). Moreover, as the individual rational choice and the utility maximizing behaviour assumptions are dropped, the analysis becomes more complex and less open for modelling (Hodgson, 2000).

In contrast to the old institutionalism, the new institutional economics builds on neoclassical theory. It adopts the assumption of individuals maximizing a given utility func- 
tion subject to constraints, which include institutions. However, it abandons the instrumental rationality assumption (North, 1995). New institutional economists acknowledge that individuals do not always behave rationally and that institutions, norms and ideologies play a major role in choices made by economic agents. Furthermore, they argue that institutions determine transaction costs that result in imperfect markets. Therefore, the perfect and efficient market found in the neoclassical economics mainstream can only be observed if there is no institution and hence no transaction cost; which is usually not the case in the real world. Leading authors associated with the new institutional economics stream include Ronald Coase, Oliver Williamson, Steven Cheung, Douglas North and Harold Demsetz. A major criticism of the new institutional economics is the assumption of given individual preferences and motivation. The framework only considers a oneway causation from individuals to institutions. Individuals can change institutions but institutions cannot change the intrinsic motivation of individuals. Individual behaviour can be temporarily changed by institutions through punishments and rewards but the individual self-seeking motivation, preferences and utility functions are taken for granted (Eggertsson, 2013).

Against the theoretical difference between old and new institutionalism we adopt in this study the common thread of the two approaches which is the recognition of institutions as the driving force of market performance. Moreover, the fact that institutional economics recognize that market and government failures may occur, but their damaging effect on market efficiency will depend on the institutional framework, makes this area particularly suitable for this study. In fact, the current design of the supply chain of fertilizer in Ethiopia is likely to generate both market failures (monopoly) and government failures (regulatory capture). Accordingly, we will investigate the presence of such failures and subsequently assess the extent to which they affect the chain efficiency.

\section{Methods}

The method used is supply chain analysis. The supply chain is the sequence of sourcing and marketing functions (Springer-Heinze, 2007). It refers to a series of decision-making processes and flows of products, information and money along a continuum from the good's import to its final use (Van der Vorst et al. 2007; Beamon I998). This approach fits well in our theoretical framework as it recognizes the chain as the result of the interaction of many institutions that need to be identified and their roles and relationships well described in order to understand the structure of the chain. Supply chain analysis is comprised of two main stages: (I) mapping the chain, (2) measuring chain performance.

Mapping the chain means to visually represent it. For this purpose, the chain functions, the main institutions and organizations need to be identified at micro, meso and macro levels. For this study, organizations are conceptualized as the actors (individuals, firms, associations, unions) that are engaged in the fertilizer market. Institutions are conceptualized as the rules and norms that shape the relations and transactions between the actors. Micro level actors include chain operators and operational service providers. Chain operators are those who perform the basic functions of the chain. They become 
the owners of the product at some stage of the chain. Operational service providers are actors who support the basic functions of the chain or perform these functions on behalf of chain operators. Meso level actors are those providing regular support services or representing the common interest of micro level actors. They perform activities that benefit several chain operators simultaneously. Macro level actors are those who develop the framework in which the business activity takes place or have an indirect influence on the chain (Springer-Heinze, 2007). In this study, the chain performance was assessed in terms of efficient and effective distribution, price gap and price competitiveness. Efficiency in this context refers to whether the chain organization is able to work with an adequate level of stock and low inventory costs. Effectiveness relates to whether farmers are provided with fertilizer on time and whether they are satisfied with fertilizer quality. Price competitiveness and price gap assessment refer to whether fertilizer is procured and delivered at the lowest possible costs. Following the assessment, the results were discussed in the light of the institutional economics framework.

\section{Research area and study units}

The selection of the research area was based on a five-stage stratified selection technique. First, one administrative region was purposively selected, according to four criteria: (I) potential for agricultural production, (2) significant fertilizer consumption and fertilizer use intensity, (3) long history of fertilizer use and (4) availability of data. According to these criteria, Oromia region emerged as the most suitable region for the study. Second, the Arsi zone was purposively selected within Oromia region according to the same criteria. The Arsi zone is a major agricultural area with most farmers having a long fertilizer use history. At the third stage of sampling, two CUs were selected in the Arsi zone according to their date of creation in order to be able to collect over an extended period of time series data of fertilizer prices. Thus, Hitosa union (created in 1992) and Gaalamaa union (created in 1993) were selected. At the fourth stage, one district was selected from those supplied by each CU. Hitosa district was selected for Hitosa union and L. Bilbiloo district for Gaalamaa union. In the fifth stage, two Primary Cooperatives (PC) were purposively selected in each district. In Hitosa district, Xaddoo Shoorimaa and Boruu Jawwii PCs were selected. In L. Bilbiloo district, Bekoji and Cibaa Mikaa'elaa PCs were selected. Figure I shows the research area on the map. 


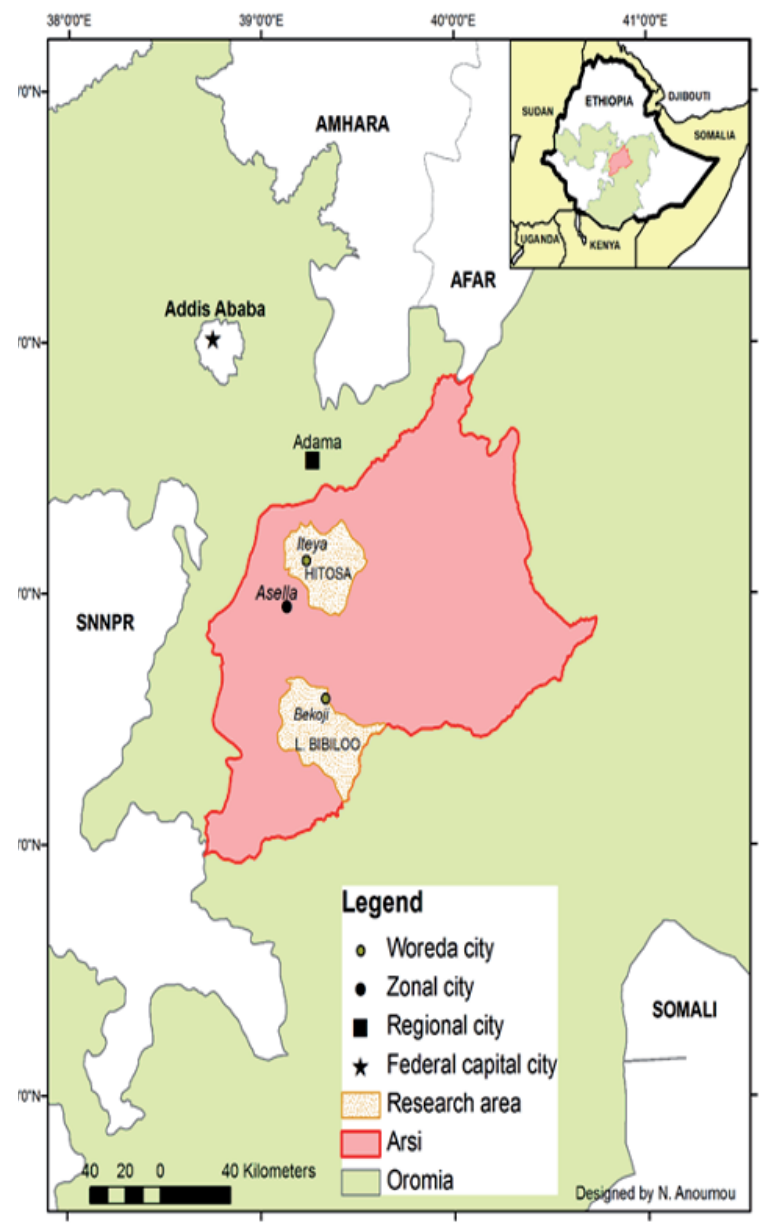

Figure 1. Map of the study area (Source: author's own illustration).

Samples were selected for the different actors (importers, wholesalers, retailers and farmers). As described above, two CUs and four PCs were selected, respectively for the wholesaler and the retailer samples. As for the farmer sample, 20 farmers were randomly selected among each of the PC's clients. As the study was focused on fertilizer and PCs were the sole retailers, farmers were randomly sampled from those coming to the PCs to purchase fertilizer. This approach was used to sample farmers who effectively use fertilizer. The samples of the study units are summarized in the Appendix. 


\section{Data collection and data processing}

Secondary data and primary data were used. Secondary data were collected through literature screening and from different databases. In the field, primary data were collected with questionnaires and interview check lists. Interview data were mainly used in a quantitative way to derive some averages presented in the text. Moreover, the information retrieved from the interviews was used to understand the functioning of the chain and to provide a background for the discussion of the results. The analyses were conducted in SPSS 16 and Microsoft Excel. The chain mapping was done during the field stay and the results were discussed with the actors and subsequently refined. Regarding the price competitiveness, time series data on retail and world prices of DAP and urea were collected. As retail prices were in the local currency, the Ethiopian Birr (ETB), the official nominal exchange rates were used to convert the retail prices in each year to the US dollar (USD).

\section{Results}

Fertilizer supply chain functions

There are four major functions along the supply chain of fertilizer in Ethiopia:

(I) import planning and inventory control

(2) import execution and domestic supply of fertilizer

(3) marketing and distribution

(4) final use.

Import planning begins with the assessment of fertilizer demand. It is a bottomup approach. At sub-district level, extension workers referred as Development Agents (DA) collect farmers' requirements, which are then gradually aggregated at district, zone and region levels by the respective Bureaus of Agriculture (BoA). The final aggregation at national level is carried out by the Agricultural Inputs Marketing Directorate of the Ministry of Agriculture (AIMD/MoA). However, in practice many manipulations occur in the process and other considerations are often taken into account. The interviews conducted during the field research showed that some DAs do not collect actual fertilizer requirements from farmers but instead report figures based on their own guesses. This makes the BoA at the upper level reluctant to use data reported by the DAs for demand aggregation. The Oromia regional BoA used to estimate the regional fertilizer demand based on home experts' guesses. In 2012, for instance, they assumed that farmers used $50 \%$ of recommended application rates over the total farmland expected to be cropped. Although experts' guesses may match reality in some cases, the overall demand estimation procedure is flawed and opaque as the base for the guesses as well at the level of the DAs as at the level of the BoA is not well documented. Inventory control is limited to central warehouses. The recorded stocks are deduced from the estimated national demand to generate the net import requirement.

Once the net fertilizer import requirement is estimated, the AISE in collaboration with the AIMD/MoA prepares the tender documents, which are reviewed and approved by an inter-departmental committee before being floated. Usually, I6 to 22 international 
companies buy the tender documents and 6 to 8 offer prices for each fertilizer product. The bids are opened and evaluated by the inter-departmental committee. Thereafter, the successful bidders are made-known and contractual agreements are signed. Thus, the AISE provides the port of Djibouti with all documents required for customs clearance and follows up fertilizer delivery to the port. When the supplier's ship reaches Djibouti, the AISE settles a letter of credit with the Commercial Bank of Ethiopia (CBE), a governmental bank, so that $90 \%$ of the contract value is transferred to the supplier's bank account. The remaining Io\% is transferred after the fertilizer has been transported to central warehouses in Ethiopia and the actual quantity supplied known. Fertilizer arrives at Djibouti in bulk. Then, the supplier bags it into $50 \mathrm{~kg}$ sacks and loads it on to trucks contracted by AISE. At the port, the quality of the fertilizer supplied is inspected by a neutral service before the loading on trucks.

With the prevailing policy, CUs are the wholesalers and the PCs the retailers. Accordingly, the AISE transports the fertilizer from Djibouti port to central warehouses, where CUs receive and store their quotas of supply. Then, CUs with the support of the zonal BoA organise the transportation of the fertilizer from central warehouses to PCs according to the quota allocated to each PC. When the supplies reach the PCs, their managers inform farmers of the availability of fertilizer. Smallholder farmers represent $92,5 \%$ of total fertilizer consumed in Ethiopia over I995-2012. In addition to smallholder farmers, the AISE directly supplies fertilizer to commercial farms, state-owned farms and research institutions. Moreover, in areas where there is no PC, the AISE is mandated to supply fertilizer to farmers.

\section{Fertilizer supply chain institutions and organizations}

Actors, transactions and rules at micro level

Two groups of actors are involved at the micro level: the chain operators and the operational service providers. Chain operators include international suppliers, importers, wholesalers, retailers and farmers. International suppliers of fertilizer are companies which often source fertilizer from Saudi Arabia, Morocco, China, Russia and Ukraine. The international suppliers transact with the importer. That transaction follows international law and is based on formal contracts which prescribe the conditions for alienation and acquisition of property rights over the physical product (fertilizer) as well as the conditions for the transfer of credit (title to money). The selection of the international suppliers also follows specific rules of public procurement.

The selection of the sole importer also follows specific rules aimed at creating equal opportunities for all previous importers to be selected. However, in reality there is a bias towards the state company AISE, which is more trusted by the organizations (AIMD/ MoA, CBE, interdepartmental committee) supervising the procurement process. In addition, the AISE employees are civil servants and are thus assumed to supply public goods and not seeking to maximize profits. This creates a biased competition with the former private importers. Also at the retail level, there is a biased competition between cooperatives and private dealers. According to Ethiopian law, agricultural cooperatives should 
aim to help farmers increase their yields and incomes by pooling their resources to support collective service provision and economic empowerment. Thus, cooperatives do not seek profits and receive support from the government. As a result, every year the AISE has been awarded the sole importer position, private dealers exited and CUs are the only wholesales while the PCs are the only retailers. The rules governing the transactions of the physical product between the AISE and the cooperatives follow a top-down approach as AISE supplies CUs with quotas of fertilizer attributed to them by the BoA and similarly, the CUs supply the PCs with quotas attributed to them as well. Farmers are the last owners of the product. They purchase from the PCs on a cash basis. Farmers in the study area purchase on average $197 \mathrm{~kg}$ of DAP and $68 \mathrm{~kg}$ of urea. Only $25 \%$ of farmers use urea while all use DAP. The fertilizer use intensity over total farmland is on average II5 $\mathrm{kg} / \mathrm{ha}$ for DAP and $37 \mathrm{~kg} /$ ha for urea. Combining DAP and urea makes the fertilizer use intensity I $52 \mathrm{~kg} / \mathrm{ha}$ (roughly $76 \mathrm{~kg} / \mathrm{ha}$ of nutrients). Fertilizer use in Ethiopia at national level over time is depicted in Figure 2. This figure shows a steady upward trend for both DAP and urea. In addition the figure illustrates an increasing share of urea in the total fertilizer use. That share increased from $5 \%$ in 1974 to $37 \%$ in 2012.

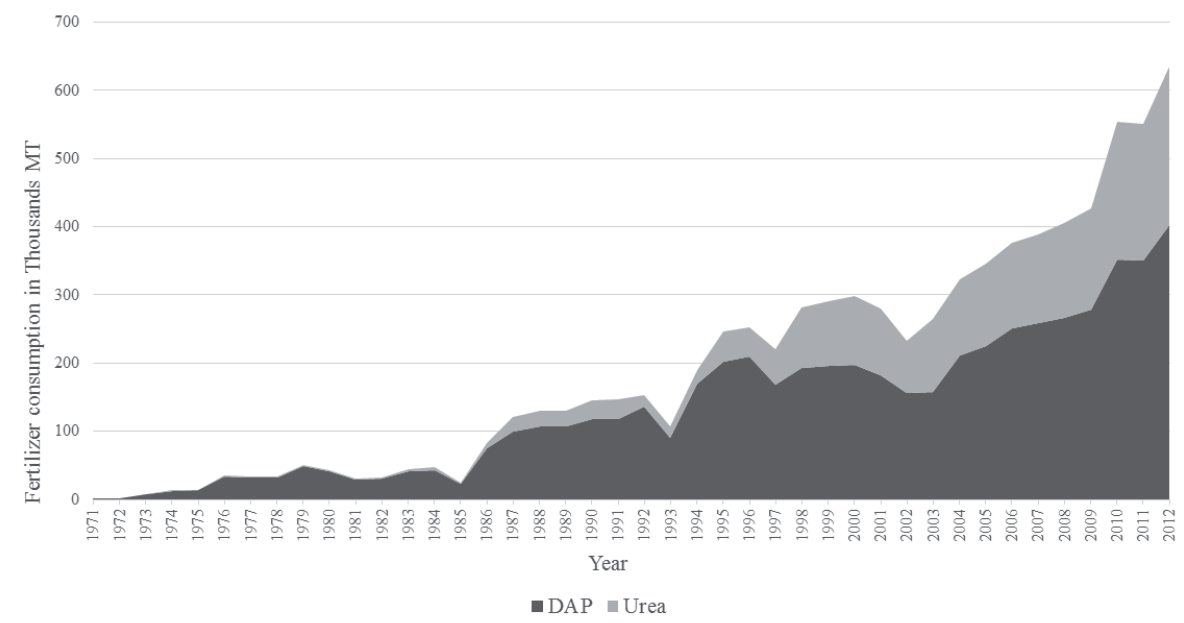

Figure 2. Fertilizer consumption in Ethiopia, 1971-2012 (Source: MoA, 2013).

Operational service providers are: transporters, banks, regional Governments, regional, zonal and district Cooperative Promotion Agencies (CPA) and zonal BoA. Transporters play an important role by moving the fertilizer from Djibouti port to the PCs. The rules governing the transactions between transporters and their counterparts are laid down in formal contracts stipulating the amount of fertilizer to be moved and the time frame. Furthermore, transporters are selected through a tendering procedure conducted by the AIMD/MoA for fertilizer to be transported between Djibouti port and central ware- 
houses and by the BoA for fertilizer to be transported from the central warehouses to the PCs. Banks are also key actors of the fertilizer supply chain. The CBE through formal credit instruments pays both the international suppliers and the AISE. It also makes the fertilizer available to cooperatives on credit guaranteed by the budget of regional governments. To supervise the credit recovery, regional governments mandate the regional CPA, which interacts with the CUs and the PCs through its lower divisions. Although in some regions there is still a $50 \%$ credit programme on fertilizer for poor farmers, this is no longer the case in the study area. PCs sell only on a cash basis to farmers. Thus, PCs pay back CUs and CUs pay back the CBE, which clears the credit. Figure 3 illustrates actors and their relations at micro level.

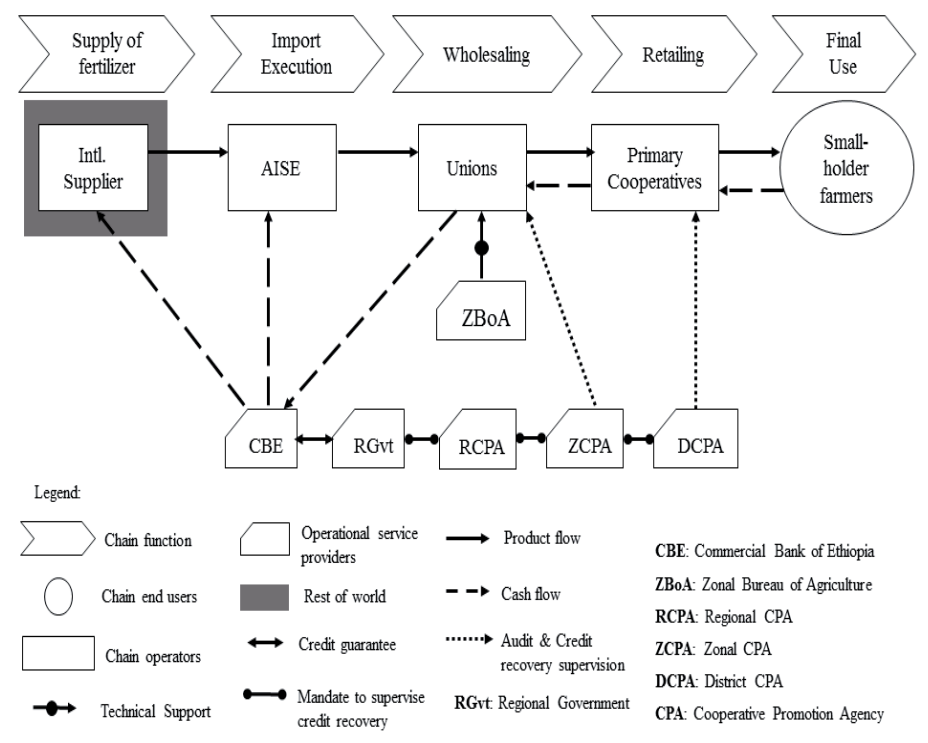

Figure 3. Fertilizer supply chain at micro level (Source: author's own illustration).

Actors, transactions and rules at meso level

Four groups of support service providers operate at the meso level along the chain: research institutions, MoA's departments, CPAs and BoAs. Several research institutions are involved in the development of the fertilizer market in Ethiopia. The leading institutions are IFPRI and the Ethiopian Development Research Institute (EDRI). Their interaction with the actors at micro level is less formal. They formulate policy options that are submitted to the actors who operate at the micro level. In some cases, they are mandated with formal contracts to assess specific stages of the chain and to formulate policy recommendations. Two departments of the MoA are involved in the fertilizer market: the extension department and the AIMD. The extension department is involved through the DAs who are in charge of building farmers' capacity on fertilizer use and of collecting 
farmers' demand for fertilizer. The interaction between the DAs and the farmers is regulated by both social institutions (norms and values) and educational institutions (training and knowledge dissemination). The AIMD is responsible for estimating national fertilizer demand and for allocating fertilizer supplies to the regions. The CPAs offer audit service and training to enhance cooperatives' capacity on fertilizer management. They are also part of the Input Coordinating Unit, which decides on margins to be allocated to both PCs and CUs. This coordinating unit also selects the central warehouses where fertilizer is supplied by the AISE. Furthermore, the unit is in charge of allocating fertilizer to CUs and PCs. It also nominates the CUs that attend the national annual fertilizer procurement planning meeting. The BoAs are involved in estimating fertilizer demand and are also part of the Input Coordinating Unit described above. In addition, they regulate the fertilizer market, track illegal dealers and monitor the quality of the fertilizer supplied.

\section{Actors, transactions and rules at macro level}

Actors at the macro level include the federal government, regional governments, public agencies, ministries and both international and multilateral organizations. The federal government defines the policies at national level. The Ministry of Finance and Economic Development is responsible for depositing the local currency equivalent amount of foreign exchange required in the treasury account. It approves the credit guarantee requested by regional Governments from the CBE. Much of the government involvement in the chain is about setting the rules and regulating the transactions between the actors at lower levels. The Agricultural Transformation Agency (ATA) is a public agency established in 2010 to support the existing actors to promote change in the agricultural sector. The ATA is running four main reforms, which will have a strong impact on the fertilizer market. The first is the Ethiopian Soil Information System, which is expected to provide a detailed picture of the nutrients that are deficient in Ethiopian soils. The second is the opening of four fertilizer blending plants which will supply fertilizer on demand, according to the results of the soil analysis. The third is the opening of two fertilizer manufacturing factories to locally produce fertilizers. Soil exploration has already started to source locally raw materials for the various fertilizers to be produced. The last reform is the new fertilizer financing system that should better connect farmers and cooperatives to microfinance institutions and remove the existing credit guarantees (ATA, 20I3). Some international agencies such as USAID and IFDC are active on fertilizer market development in Ethiopia. They mostly interact with government bodies through international or bilateral agreements to channel funds and technical support to the actors at micro level.

\section{Chain performance assessment}

\section{Chain efficiency}

The level of stocks in Arsi zone over time, as depicted in Figure 4a, shows that there has been a dramatic increase in left-over stocks in recent years. Although the level of stocks was relatively stable until 2008, the graph shows that it started to increase slowly 
between 2009 and 2010 and then sharply afterwards. This shows a striking correspondence between the rise of the stocks and the implementation of the sole importer policy alongside the government control of the entire chain. This correspondence is confirmed by the interviews conducted with the CU and PC managers who highlighted that fertilizer stocks started to increase during the last restructuring of the chain, which resulted in theimposing of quotas that were related to neither their marketing capacity nor the farmers' requirements. Fig. 4 b shows that in relative terms, stocks exceeded half of the total fertilizer supplied in that year. This situation is not just limited to our study area. In fact, data collected from AISE revealed that at a national level, left-over stocks were $42 \%$ of total available DAP and 50\% for urea in 2012. Fig. $4 \mathrm{~b}$ also points out the decreasing trend in the share of fertilizer consumption relative to estimated demand. In 2012, the amount of fertilizer consumed was just half of the estimated amount.

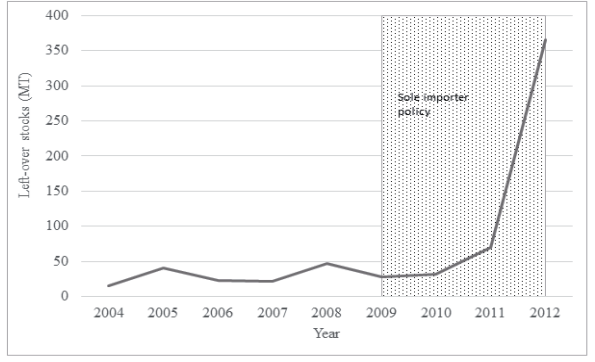

a. Fertilizer stocks trend

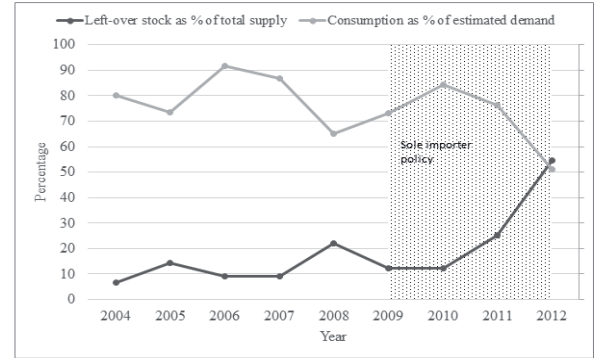

b. Shares of stocks and consumption in supply and demand estimate

Figure 4. Fertilizer market performance in Arsi zone, 2004-2012. (Source: Arsi Zonal Bureau of Agriculture, 2013).

\section{Chain effectiveness}

In the study area, the majority of farmers report that they received fertilizer on time. Only $\mathrm{I} .2 \%$ of them reported late delivery as a major constraint. Although, only $2.5 \%$ of them reported the low quality of the fertilizer supplied as a major constraint, most of them reported this as a secondary constraint. Actually, they complain about receiving old stocks of fertilizer, whose quality in their opinion is lower than the quality of the new supplies.

\section{Price competitiveness}

The major constraint reported by $87.5 \% 3$ of farmers is high fertilizer prices. In this section we investigate price competitiveness by comparing the AISE's prices at Djibouti port and world market prices. The study focuses on two supply agreements that were sig- 
ned in October 20II and January/February 20I2, while the product was delivered respectively in January 2012 and in May 20I2. As international suppliers try to anticipate fertilizer prices at delivery time when submitting their bids, the prices at contract agreement time are compared to world prices not only at the time of contracting, but also at delivery time (Table I). Since available world prices are free on board (fob) prices, while the AISE uses cost and freight ( $\mathrm{cfr}$ ) prices, the average difference between $\mathrm{cfr}$ and fob prices was added to cfr prices. This difference includes the costs of freight and the loading in trucks at the port. This average difference was estimated to 95 USD/MT in 2012 by IFPRI.

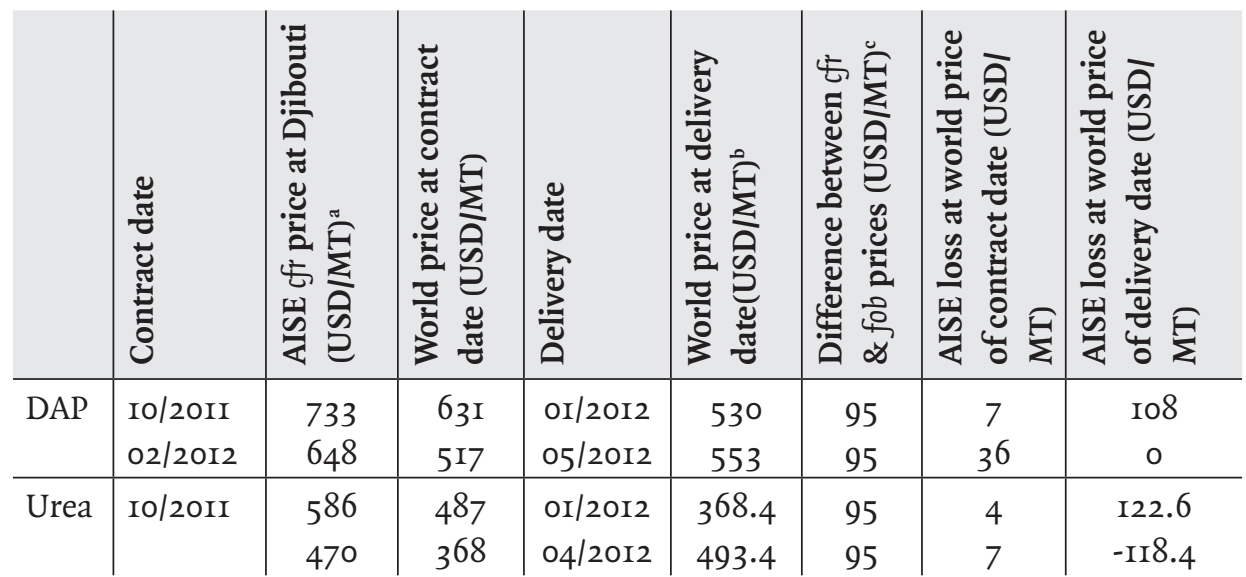

Table 1. AISE procurement and international price of fertilizer, 2011-2012 (Source: IFPRI, 2012; AISE, 2013; WB, 2014). a: MoA / AISE (IFPRI, 2012)

b: World Bank Commodity prices (World Bank, 2014)

c: Fertilizer Weekly estimate (IFPRI, 2012) 
Comparing AISE's procurement prices and world market prices at contract dates shows that for the two procurement periods prices given to the AISE were slightly higher than prices on world markets for both DAP and urea. Weighting prices with quantities imported ${ }^{4}$ gives an average of ${ }_{3} 3$ USD/MT paid by the AISE above world market prices at contract dates, which is equivalent to about $2 \%$ of the weighted world price at the time of contract. Considering world market prices at delivery dates, the results show that the AISE paid substantially higher rates than world market prices for the first tender and lower than world market rates for the second tender. Weighting prices with quantities imported gives an average of 66.7 USD/MT paid by the AISE above world market prices at delivery dates, being equivalent to about $\mathrm{I} 4 \%$ of the weighted world price at delivery time.

\section{Price gap assessment}

Between I97I and 2012, the price gap between world market and retail prices of fertilizer were on average 67 USD/MT for DAP and 40 USD/MT for urea. In relative terms, the price gap makes up respectively $40 \%$ and $62 \%$ of the retail price for DAP and for urea (Figure 5). This price gap can be further divided into international and domestic costs. International costs make up respectively $22 \%$ and $\mathrm{I}_{3} \%$ of the retail price for DAP and for urea. These costs include international freight, bank charges for letters of credit, clearing and transit costs, quality inspection fees, transportation costs between Djibouti and Ethiopia, AISE margin, bagging and spillage costs. The domestic costs are respectively I $6 \%$ and $49 \%$ of the retail price of DAP and of urea. They include loading and unloading costs, warehouse rents, bank interest, transportation costs between central warehouses and PCs, CU and PC margins and a margin associated with the stocks. This margin is calculated as the difference between the price of the new supply and the initial price of the stocks supplemented with the storage costs. The final retail price is in fact a weighted average of the price of the new supply and the price of fertilizer in stock. The margin for AISE, CUs and PCs is fixed by the MoA. In 20I2, the margin was set at 0.84 USD/MT for AISE, 3.09 USD/MT for CUs and 3.95 USD/MT for PCs. The marketing margins for all actors involved in fertilizer distribution put altogether represented about $3.2 \%$ of the price gap for DAP and $3 \cdot 9 \%$ of the price gap for urea in 2012 . 


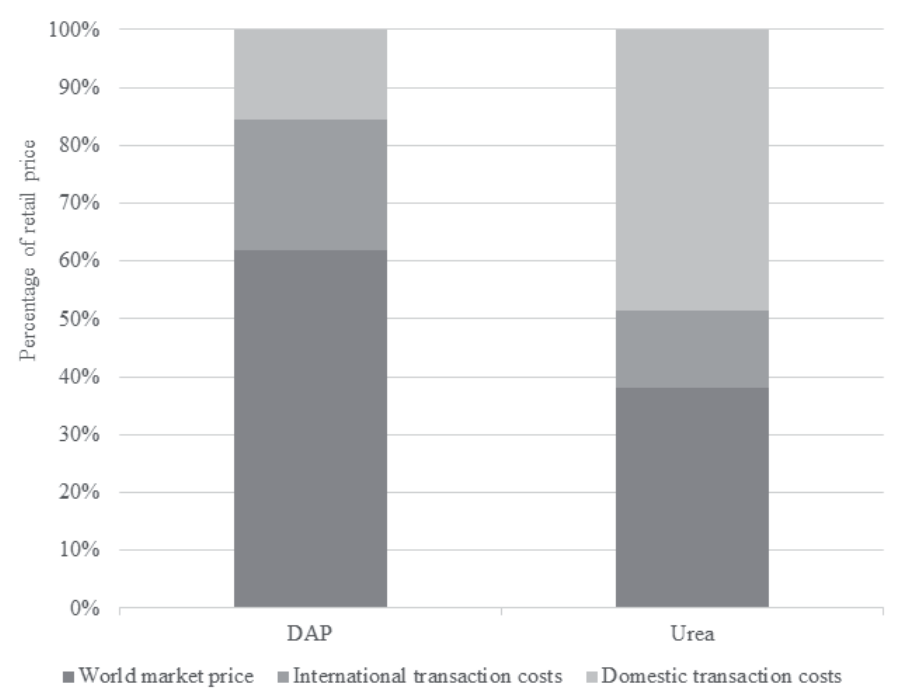

Figure 5. Composition of retail price of DAP and urea, averages from 1971-2012.

(Sources: World Bank, 2014; AISE, 2013; EDRI, 2013; PC, 2013).

\section{Discussion}

The study shows that several institutions both formal and informal regulate the fertilizer market in Ethiopia. Formal rules such as public procurement procedures and written contracts regulate the transactions in many cases and enforcement mechanisms through supervision of the procurement implementation as well as national and international laws are present. Informal institutions such as societal norms and customs regulate the day-to-day interaction between the different actors. The key actors in the fertilizer market are: the state, agricultural cooperatives, research institutions and international organizations. The study points out that the recent centrally-organized structure of the chain has resulted in some government and market failures. Explicitly, there is a state monopoly over fertilizer importation but also a cooperative monopoly over fertilizer distribution. Nevertheless, the study did not find any evidence the AISE nor the cooperatives abuse their monopoly position. In fact, the price competitiveness assessment shows that the import price paid by the AISE is only $2 \%$ above world-equivalent price at contract agreement time. The price difference between contract agreement time and fertilizer delivery time is higher by about $14 \%$. However, this price difference is highly subject to price volatility that is a typical feature of international fertilizer markets. In addition to price competitiveness, the price gap assessment shows that most of the price gap is related to unavoidable transaction costs such as: transportation costs and clearing and transit at the port. The marketing margins received by the AISE and the cooperatives forms a 
small fraction of the price gap (3-4\%). In a nutshell, margins between retail and import prices of fertilizer in Ethiopia are competitive. As reported by Heisey and Norton (2007), these margins in Ethiopia compare favourably with other African countries, though are still higher than in Asian and Latin American countries. Similarly, Rashid et al. (2013) showed that fertilizer prices in Ethiopia are significantly lower than in neighbouring Kenya, Uganda, Rwanda and Tanzania. An explanation for such "low" prices is the state control over prices and marketing margins. Such control restricts the self-interest behaviour of fertilizer dealers (AISE and cooperatives). Moreover, in terms of quantity, both the AISE and the cooperatives are subject to imposed quantities of fertilizer they should import and distribute. Thus, despite their monopoly they cannot restrict quantity in order to maximise their monopoly gains.

The study did not find any evidence of large-scale corruption or collusion between the AISE and the international suppliers to seek financial gain during fertilizer procurement. In fact, the process of tender floating and bid opening seems transparent and is supervised by an inter-departmental committee. These examples are in line with the theoretical background of institutional economics, arguing that market and government failures may not matter as much, as long as other institutions beside the state and market are involved in the market regulation. In the case of fertilizer in Ethiopia, we saw that strict rules for public procurement and enforcement mechanisms via laws play a significant role in regulating the market. Additionally, the absence of corruption and payment-seeking behaviours can be explained from the old institutionalism perspective by the internalization of publicly-oriented values by individuals working for the AISE, the cooperatives and the Ministries. From the new institutionalism perspective, this can be interpreted as a response to the punishments and incentives created by the law in force in the country. However, a psychological analysis is needed to clarify the real motives of individuals that could explain the behaviour observed and provide support to either the old or the new institutionalism explanation. Such analysis is beyond the scope of this study.

Although there is no evidence of market failures in terms of corruption or monopolygains, the study points to imperfections in the demand estimation procedure. The arbitrary assumptions made by both the DAs and the BoA officers in charge of estimating demand, instead of reporting and relying on farmers' actual requirements are the driving factor behind the exponential increase in left-over stocks of fertilizer. The introduction of complex assumptions, tools and guesses in the estimation of fertilizer demand by the home experts of the BoAs can be analysed from the new institutional economics perspective as a way for BoA officers to maximize their utility by increasing their influence over the process. Similar analysis has been made by Nedergaard (2006), when analysing the common agricultural policy (CAP) of the EU. He postulated that the complexities introduced in the CAP are a way for the EU bureaucrats to maximize their utility by increasing their influence over the process and expanding their career possibilities as well as their power base. 
The increasing stocks of fertilizer lead to two consequences. First, farmers are not happy when supplied with old stock fertilizer, as they believe new supplies would be more effective. Although our discussions with experts did not point out a decrease in fertilizer effectiveness due to long storage periods, this perception of farmers needs to be addressed through awareness campaigns. Second, and probably the most important problem related to keeping large stocks, is that the storage costs are transmitted to the retail price the next year, making fertilizer more expensive for farmers. As argued by IFPRI (20I2), the current level of stocks of about $50 \%$ of total supply far exceeds the optimal level of reserves that is needed and which should be no more than 10\% of the supply. In order to show the order of size of economic losses, IFPRI (20I2) calculated that the resources diverted in managing fertilizer stocks could have supported more than 130.000 productive safety net programme beneficiaries. Therefore, there is an urgent need to reduce the stock levels. Doing so will also requirea change in the demand estimation procedure, which considers only stocks at central warehouse level. The stock inventory should be conducted both at central warehouse and cooperatives' warehouses levels and be incorporated in the import need estimation.

\section{Conclusion}

Fertilizer is a key input in boosting agricultural production in Ethiopia. Hence, increasing its use in the country has been targeted as a strategic goal. To achieve that goal, the government has implemented over time various policies on the fertilizer market. The last policy shift was characterized by the state control of the chain, a control over prices but also the involvement of non-state organizations such as agricultural cooperatives in the chain. In this study, we analysed the structure of the chain in the light of an institutional economics framework and assessed the chain performance through effectiveness, efficiency and price competitiveness indicators. The findings showed that several formal and informal institutions regulate the fertilizer market. Both market and government failures were observed but they did not affect the performance of the market as much because the institutions in place have shaped the behaviour of the individual actors, especially those working in the public sphere, in such a way that they do not seek to maximize personalgains. The supply chain of fertilizer was found to be effective in supplying farmers in a timely manner. However, the chain efficiency could be improved and fertilizer price be lowered by reducing stocks and storage costs as well as improving the demand estimation process.

In fact, the study pinpoints a striking correspondence in rising stocks and the state control of the chain. These rising stocks are explained by the arbitrary assumptions guiding the demand estimation process. Therefore, the study suggests improving the current approach by firstly setting incentives and punishments to make sure that farmers' actual requirements are reported by the development agents. Secondly, at the level of the bureaus of agriculture, experts' knowledge (which we recognize as useful) should complement and not replace field information about farmers' actual requirements. Assumptions made when aggregating national fertilizer demand should be based on well documented 
information and not rough estimates. Thirdly, the estimation of the import requirement should consider stock inventories at both central warehouse level and cooperative level. The stockholding policy should target no more than Io\% of fertilizer supply as reserves, in order to avoid locking up scarce resources into fertilizer stockholding. Finally, this study could be extended in two directions. First, a psychological analysis is required to determine whether the unselfish behaviour we observed in the public sphere was due to internalizing altruism values or was dictated by incentives and punishments created by the institutions. The second direction is to analyse how the different policy settings (state control and liberal market) that occurred over time on fertilizer markets have affected price for fertilizer in Ethiopia.

\section{Acknowledgements}

Comments and suggestions by two anonymous reviewers are gratefully acknowledged. Funding for this research was provided by foundation fiat panis and the German Academic Exchange Service (DAAD). Comments and suggestions by Jonas Luckmann, Bamlak Alamirew and Francis Shitawa are gratefully acknowledged. Research for this paper was conducted between the Food and Agricultural Policy Group of the University of Hohenheim and the Centre for Rural Development Studies of Addis Ababa University.

\section{References}

ATA (2013). Proposal for revised input credit system. http://www.ata.gov.et, accessed on June I6, 2013.

AISE (2013). Unpublished data. Addis Ababa, Ethiopia: Agricultural Inputs Supply Enterprise Archives.

Arsi Zonal BoA (2013). Unpublished data. Assela, Ethiopia: Arsi Zonal Bureau of Agriculture Archives.

Barbier, E.B. (2000). The economic linkages between rural poverty and land degradation: some evidence from Africa. Agric. Ecosyst. Environ. 82, 355-370.

Chang, H.-J. (2009). Rethinking public policy in agriculture: lessons from history, distant and recent. J. Peasant Stud. 36, 477-515.

_ (2003). Globalization, economic development and the role of the state. Zed Books, p. 335.

(2002). Breaking the mould: an institutionalist political economy alternative to the neo-liberal theory of the market and the state. Camb. J. Econ. 26, 539-559.

Coase, R. (1998). The new institutional economics. Am. Econ. Rev. 72-74.

Commons, J.R. (I93I). Institutional economics. Am. Econ. Rev. 648-657.

Crawford, E.W., Jayne, T.S., Kelly, V.A. (2006). Alternative approaches for promoting fertilizer use in Africa. Agriculture \& Rural Development Discussion Paper 22. Washington, DC: World Bank Press, p. 87.

Demeke, M., Said, A., Jayne, T.S. (1997). Promoting fertilizer use in Ethiopia: The implications of improving grain market performance, input market efficiency, and farm management. Grain Market Research Project Working Paper 5. Addis Ababa, Ethiopia: Ministry of Economic Development and Cooperation Press, p. 50.

Dercon, S., Christiaensen, L. (20II). Consumption risk, technology adoption and poverty traps: evidence from Ethiopia. J. Dev. Econ. 96, 159-173.

EDRI (2013). Unpublished data. Addis Ababa, Ethiopia: Ethiopian Development Research Institute Archives.

Eggertsson, T. (2013). Quick guide to new institutional economics. J. Comp. Econ. 4I, I-5.

Gregory, D.I., Bumb, B. (2006). Factors affecting supply offertilizer in Sub-Saharan Africa. Agriculture \& Rural Development Discussion paper 24. Washington, DC: World Bank Press, p. 8I. 
Heisey, P.W., Norton, G.W. (2007). Fertilizers and other farm chemicals. Handb. Agric. Econ. 3, 274I-2777.

Hodgson, G.M. (2000). What is the essence of institutional economics? J. Econ. Issues 317-329.

Hodgson, G.M. (1998). The approach of institutional economics. J. Econ. Lit. I66-I92.

Howard, J., Crawford, E., Kelly, V., Demeke, M., Jeje, J.J. (2003). Promoting high-input maize technologies in Africa: the Sasakawa-Global 2000 experience in Ethiopia and Mozambique. Food Policy 28, 335-348.

IFPRI. (20I2). Fertilizer in Ethiopia: Policies, Value Chain, and Profitability. Addis-Ababa, Ethiopia: International Food and Policy Research Institute Press, p. 66.

Krueger, A.O. (I99I). Government failures in development. National Bureau of Economic Research working Paper 3340. Cambridge, USA: NBER Press, p. 26.

Matsumoto, T., Yamano, T. (2009). Soil fertility, fertilizer, and the maize green revolution in East Africa. World Bank. Policy Research Working Paper 5158, World Bank Press, p. 36.

Mwangi, W.M. (1996). Low use offertilizers and low productivity in Sub-Saharan Africa. Nutr. Cycl. Agroecosystems 47, I35-I47.

Nedergaard, P. (2006). Market failures and government failures: A theoretical model of the common agricultural policy. Public Choice I27, 385-405.

North, D.C. (1995). The new institutional economics and third world development. New Institutional Econ. Third World Dev. 17-26.

PC (2013). Unpublished data. Eteya, Ethiopia: Primary Cooperatives Archives.

Rashid, S., Tefera, N., Minot, N., Ayele, G. (2013). Fertilizer in Ethiopia: An assessment of policies, value chain, and profitability. IFPRI Discussion Paper 01304, p36.

Rutherford, M. (1995). The old and the new institutionalism: can bridges be built? J. Econ. Issues 443-45I.

Spielman, D.J., Byerlee, D., Alemu, D., Kelemework, D. (2010). Policies to promote cereal intensification in Ethiopia: The search for appropriate public and private roles. Food Policy 35, I85-I94.

Springer-Heinze, A. (2007). GTZ-Value Links Manual: The methodology of Value Chain Promotion. Eschborn, Germany: GTZ Press, p. 255.

Tanzi, V. (20II). Government versus markets: The changing economic role of the state. New York, USA: Cambridge University Press: p. 390.

Van der Vorst, J.G.A.J., Da Silva, C.A., Trienekens, J.H. (2007). Agro-industrial supply chain management: concepts and applications. Occasional Paper 17 , FAO press, p. $7 \mathrm{I}$.

Vanlauwe, B., Wendt, J., Giller, K.E., Corbeels, M., Gerard, B., Nolte, C. (20I4). A fourth principle is required to define Conservation Agriculture in Sub-Saharan Africa: The appropriate use offertilizer to enhance crop productivity. Field Crops Res. I55, I0-I3.

Wolford, W., Borras, S.M., Hall, R., Scoones, I., White, B. (2013). Governing global land deals: the role of the state in the rush for land. Dev. Change 44, I89-2Io.

Word Bank (20II). Ethiopia Emergency Food Crisis Response Programme: Fertilizer Support Project Report No.: 62834. IEG Public Sector Evaluation. Washington, DC: World Bank Press, p. 47.

(2014). World Bank Commodity Price Data (The pink sheet), annual prices, I 960 to present, nominal US dollars, updated on June 3, 20I4. http://econ.worldbank.org/WBSITE/EXTERNAL/EXTDEC/EXTDECPROSPECTS/o,,contentMDK:21574907ffimenuPK:785923IffipagePK:64I6540Iffipi PK:64I65026ffitheSitePK:476883,00.html. Accessed on June 23, 2014.

Yamano, T.Y., Kijima, Y.K. (2010). Market Access, Soil Fertility, and Income Market Access, Soil Fertility, and Income in East Africa in East Africa. GRIPS Discussion Paper Io-22. Tokyo, Japan: GRIPS Press, p. 29

Zerfu, D., Larson, D. (2010). Incomplete markets and fertilizer use: evidence from Ethiopia. World Bank Policy Res. Work. Pap. Ser. Vol. 


\begin{tabular}{l|l|l|l|c} 
Union & District & $\begin{array}{c}\text { Primary Cooperatives } \\
\text { (PC) }\end{array}$ & Sub-district & $\begin{array}{l}\text { Number } \\
\text { of farmers } \\
\text { surveyed }\end{array}$ \\
\hline Hitosa & Hitosa & Xadoo Shoorimaa PC & Gondee Fichama & I7 \\
\hline Union & & & Jango Kilisa & 2 \\
\hline & & & Debeya Adere & I \\
\hline & & Boruu Jawii PC & Sub-total & $\mathbf{2 0}$ \\
\hline & & & Jawi Cilaloo & 8 \\
\hline & & & Oda Jila & 2 \\
\hline Gaalamaa & L. Bilbiloo & Bekoji PC & Boruu Cilaloo & 2 \\
\hline Union & & & Sub-total & $\mathbf{2 0}$ \\
\hline & & & Dawa Bursa & 9 \\
\hline & & & Bekoji Negoso & 7 \\
\hline & & & L/Diimaa & 3 \\
\hline & & & Koji Ketara & I \\
\hline & & & Sub-total & $\mathbf{2 0}$ \\
\hline & & & Cibaa Mikaa'elaa & $\mathbf{2 0}$ \\
\hline & & & Sub-total & 20 \\
\hline & & & 80
\end{tabular}

Appendix: Summary of study units. Source: Field survey, 2013. 